\title{
Filicídio: de Medéia a Maria
}

\author{
Filicide: from Medea to Mary
}

\author{
Lisieux Elaine de Borba Telles ${ }^{1}$, Paulo Soroka ${ }^{2}$, Ruben de Souza Menezes ${ }^{3}$ \\ ${ }^{1}$ Mestre em Psiquiatria Forense, Universidad Nacional de La Plata, La Plata, Argentina. Doutoranda, Universidad Nacional de La Plata. Médica \\ psiquiatra, Instituto Psiquiátrico Forense Maurício Cardoso, Porto Alegre, RS. ${ }^{2}$ Médico psiquiatra, Instituto Psiquiátrico Forense Maurício Cardoso. \\ ${ }^{3}$ Mestre em Medicina e Clínica Médica, Universidade Federal do Rio Grande do Sul (UFRGS), Porto Alegre, RS. Médico psiquiatra, Instituto \\ Psiquiátrico Forense Maurício Cardoso e Centro Interdisciplinar de Saúde Mental (CISAME), Porto Alegre, RS.
}

\section{Resumo}

O filicídio é a manifestação extremada da violência doméstica contra a criança. Visando estudar o tema e chamar a atenção para a sua importância, os autores apresentam a descrição de uma perícia psiquiátrico-forense realizada no Instituto Psiquiátrico Forense Dr. Maurício Cardoso, de Porto Alegre, referente a um caso de duplo filicídio, seguido de tentativa de suicídio. O contexto jurídico em relação ao delito de filicídio é brevemente apresentado, assim como uma revisão de literatura do tema. É destacado o papel da doença mental grave como fator associado a certos casos de conduta filicida e sublinhada a relevância do diagnóstico precoce e da implementação de medidas terapêuticas adequadas. Os autores assinalam a necessidade do olhar atento dos agentes de saúde mental para a identificação de casos indicativos de violência contra a criança, uma vez já ser conhecida a tendência à subnotificação desses casos.

Descritores: Psiquiatria forense, filicídio, infanticídio, homicídio, violência.

\begin{abstract}
Filicide is the extreme domestic violence against the child. To study the subject and draw attention to its importance, the authors present the description of a forensic-psychiatric investigation that was performed at Instituto Psiquiátrico Forense Dr. Maurício Cardoso, in Porto Alegre, Brazil. This investigation refers to a double filicide followed by a suicide attempt. The legal context and a literature review on the subject are briefly presented in this work. The role of severe mental disease is stressed as a factor associated with certain cases of filicide behavior. The authors report the importance of early diagnosis and the need to implement appropriate treatment. Attention by mental health professionals is necessary to identify likely cases of violence against the child, since these cases are known to be underreported.
\end{abstract}

Keywords: Forensic psychiatry, filicide, infanticide, homicide, violence.

"Medeia, apontando para as crianças mortas. Elas já não existem. Sofrerás por isso, Jáson.” *

\section{Introdução}

A menção ao assassinato dos filhos pode parecer, à primeira vista, uma referência exagerada a respeito de fatos excepcionais. Segundo dados do Ministério da Saúde, entretanto, no período de 1990 a 2000 ocorreram

\footnotetext{
* Eurípides, 431 a.C.
}

211.918 mortes de crianças e adolescentes por acidentes e violências, sendo que, na população compreendida entre os 5 e os 19 anos, as causas externas aparecem como a principal causa de morte, superando inclusive as doenças infecciosas e parasitárias ${ }^{1}$. A realidade mostra, além disso, que em se tratando de vítimas infantis os agressores são, em geral, os próprios pais. Já os desconhecidos são os maiores responsáveis por agressões praticadas contra adolescentes e adultos ${ }^{1-3}$.

A idealização do amor das mães pelos seus filhos e a subjacente negação dos aspectos agressivos que, em diferentes graus, se fazem presentes no âmbito desse

\section{Correspondência:}

Lisieux E. de Borba Telles, Av. Caçapava, 537/402, CEP 90460-130, Porto Alegre, RS. E-mail: lisieux@telles.med.br. 
relacionamento são fatores que, por motivos defensivos, obstaculizam o pleno reconhecimento da agressão reiterada sobre os filhos, tanto em suas expressões mais silenciosas - o abandono, a negligência - como em sua manifestação mais extremada: o filicídio ${ }^{4}$. Este último adquire expressão mais ampla, como aponta Rascowsky, quando destaca que a sociedade como um todo destrói, mutila e mortifica aos jovens, como ocorre nos tempos de guerra 5 .

Movimento importante no sentido do progressivo reconhecimento da violência doméstica contra crianças, em sua ampla gama de manifestações, ocorreu no início da década de 60, quando Kempe descreveu a síndrome da criança espancada, a qual inclui lesões diversas, causadas por diferentes tipos de golpes, injúrias e traumatismos, conduzindo à morte da vítima em $25 \%$ dos $\operatorname{casos}^{6}$. Os casos conhecidos representam apenas a quarta parte daqueles que ocorrem nas comunidades, sendo que a maior parte deles, ao não ser denunciada, não recebe o encaminhamento necessário. Além disso, apenas uma minoria das mulheres que cometem infanticídio é condenada e, quando isso ocorre, as sentenças existentes são leves ${ }^{7-9}$.

Entretanto, é significativa a oposição cultural a aceitar a realidade do assassinato dos filhos. Esse estado de coisas encontra expressão significativa na semântica: até meados da década de 70, o termo "filicídio" não constava em importantes publicações americanas, sendo "infanticídio" o termo mais próximo existente ${ }^{5}$. Esse fato vai ao encontro da negação e subnotificação da violência doméstica, sob a alegação da ainda "sagrada família"10. Paradoxalmente, a atitude criminosa dos pais encontra expressão clara na mitologia, onde aparece de modo reiterado o assassinato do primogênito, seguido de ameaças ou mutilação parcial perpetradas aos irmãos. $\mathrm{Na}$ tragédia grega, Medéia mata seus dois filhos como forma de retaliação a Jasão, seu cônjuge traidor. $\mathrm{Na}$ Grécia e Roma antigas, o assassinato de recém-nascidos era tido como um direito do chefe de família, como forma de determinar a descendência legal ${ }^{11}$. Na Idade Média, ainda que considerado ilegal, o fato era tolerado, como forma de controlar o tamanho da família.

Levantamento realizado pela Associação Brasileira Multiprofissional de Proteção à Infância e à Adolescência (ABRAPIA) destaca que 44,3\% dos homicídios contra crianças ocorrem no âmbito doméstico, sendo que em $34,4 \%$ dos casos são os parentes os responsáveis ${ }^{1}$. $\mathrm{O}$ assassinato de bebês nas primeiras 24 horas de vida é quase sempre praticado por suas mães, não havendo diferença quanto ao sexo da vítima ${ }^{12}$

Resnick revisou a literatura científica sobre o assassinato de crianças por seus pais no período compreendido entre 1751 e 1967 , dividindo os agressores em dois grupos:
- Neonaticidas: aqueles que assassinaram o filho nas primeiras 24 horas de vida. Nesse grupo, não houve predomínio de transtornos psicóticos, mas sim de gravidez indesejada, devido à ilegitimidade, estupro ou por ser a gravidez vivenciada como obstáculo à ambição dos pais.

- Filicidas: aqueles que mataram o filho após as 24 horas. O autor subdividiu esse grupo em: filicídio altruístico, filicídio psicótico, filicídio da criança indesejada, filicídio acidental e o filicídio como uma revanche ao esposo (Medéia) ) $^{13,14}$.

No Brasil, Mendlowicz et al. estudaram a população de mulheres que mataram seu filho nas primeiras 24 horas, na cidade do Rio de Janeiro, no período de 1900 a 1995 . Embora houvesse relato de queixas psiquiátricas, apenas uma das acusadas recebeu o diagnóstico de retardo mental, sendo as demais consideradas sãs, do ponto de vista psiquiátrico $0^{7,11}$.

A importância da doença mental como determinante do filicídio tem sido destacada por diversos autores ${ }^{13,15-}$ ${ }^{18}$. Castaño-Henao, em um estudo realizado com a população filicida da Colômbia, durante os anos de 1998 a 2003, encontrou predomínio de mães como agentes dessa violência e a presença de maus tratos crônicos como fator de risco para esse crime. A pesquisadora destacou como causas de tal conduta a doença mental, seguida pelo filicídio acidental. As mães filicidas psicóticas utilizaram mais as armas, eram mais velhas e mataram crianças com mais idade quando comparadas com o grupo de mães não-psicóticas ${ }^{19}$.

Menezes destacou que, em se tratando de doentes mentais, ocorre uma distorção delirante do pensamento, sendo a conduta filicida expressão da ideação delirante. Cita um caso ocorrido no Instituto Psiquiátrico Forense (IPF): a mãe tentou assassinar seu filho sob influência de ideação mística, pela qual acreditava que, com o sacrifício da criança, a família seria poupada de influências demoníacas ${ }^{16}$.

É nosso propósito, ao apresentar relato de perícia psiquiátrico-forense de responsabilidade penal realizada no IPF em que o delito foi o de filicídio, chamar a atenção para as vicissitudes da violência familiar, em suas variadas manifestações, bem como destacar a associação entre doença mental grave não-tratada e conduta violenta. Sabe-se que tais fenômenos, se adequadamente diagnosticados e tratados, poderão ser evitados ou minimizados. A pericianda, através de consentimento informado, concordou com o estudo de seu caso.

\section{Contexto jurídico}

$\mathrm{O}$ assassinato de filhos pela mãe pode receber os seguintes enquadramentos no atual Código Penal (vigente desde 1940), de acordo com a situação $0^{20}$ : 
- Artigo 123 - filicídio, ou seja, "matar sob a influência do estado puerperal, o próprio filho, durante o parto ou logo após".

- Artigo 121 - homicídio.

No sistema penal brasileiro, o agente do delito de filicídio recebe pena menor do que a prevista para o delito de homicídio. Para tal, é necessário que fique comprovada, na perícia psiquiátrica, a existência do "estado puerperal" e também a presença de nexo causal com o delito. Este exame pode ocorrer já na fase de inquérito, buscando uma maior proximidade temporal com os fatos.

Quanto ao nexo causal, ainda que o filicídio muitas vezes seja descrito como causado por um fenômeno transitório do puerpério, acredita-se que possa estar mais relacionado a outros fatores, como psicopatologia prévia $^{21}$.

Nos casos de homicídio em que ocorre dúvida quanto à integridade mental da mãe, o juiz, baseado no artigo 149 do Código de Processo Penal, poderá instalar o incidente de insanidade mental, suspendendo o processo até o recebimento do resultado da perícia de responsabilidade penal ${ }^{22}$.

No estado do Rio Grande do Sul, o IPF centraliza as perícias penais e realiza o tratamento dos réus que recebem uma medida de segurança por serem considerados inimputáveis por doença mental.

\section{Relato sumarizado de perícia}

M., 26 anos, separada, do lar. Comparece para avaliação na condição de ré presa e confessa por denúncia de homicídio das duas filhas. Nos antecedentes mórbidos pessoais, verificou-se história de duas internações psiquiátricas no passado, tendo numa delas apresentado ideação suicida e alucinações auditivas; na outra, apresentava taquilalia, euforia, insônia, delírios de grandeza. Houve, igualmente, tentativa pretérita de filicídio. Houve hipótese diagnóstica de transtorno afetivo bipolar.

Em sua história, aparece a separação dos pais, bem como uma primeira crise na adolescência, com internação. Aos 19 anos, conheceu seu companheiro, e foram morar juntos quando se soube grávida. Tiveram ao todo duas filhas. O companheiro, ciumento, costumava agredi-la fisicamente. Havia brigas freqüentes, em que ocorria o descontrole de ambos, que quebravam objetos da casa. Um ano antes do delito, após uma violenta briga, o companheiro quis a separação. Nessa época, M. passou a ter interesses religiosos. Quando o companheiro quis voltar para casa, após o término de um novo relacionamento que iniciara, percebeu-se, em suas próprias palavras, "paranóica": "ele me tratava como se fosse uma prostituta, fazia de tudo na cama, e eu fiquei com ódio dele. Depois, quando eu quis ficar com ele, ele não quis mais: queria ficar com as outras". Nesse período, vivenciava um conflito entre os interesses religiosos e as demandas sexuais do companheiro.

A pericianda descreveu-se como uma mãe cuidadosa com suas filhas e que gostava muito delas. J., o ex-companheiro, contou que M. apresentou períodos de insônia, perda de iniciativa, mutismo. Nessas ocasiões, era descuidada com as filhas. Houve, também, referência a períodos de agitação, irritabilidade, agressividade, conduta "acelerada", idéias de grandeza e violência. Houve uma ocasião em que ateou fogo à casa, colocando as filhas e a si mesma em risco. Apresentou idéias místicas, em que se referia ao companheiro como "Judas" ou, alternativamente, "o diabo".

A pericianda assim descreveu o delito que praticou:

"Eu matei minhas filhinhas, uma de 3 e outra de 5 anos, e depois queria me matar: cortei os pulsos e a garganta, não consegui. Eu estava há 2 semanas sem dormir, tomava clorpromazina e imipramina há 3 anos, mas não estava adiantando. Fiquei nervosa. $\mathrm{O}$ meu exmarido ficava comigo e com outras. Fiz isso pra me vingar dele. Eu estava nervosa e não tinha quem me ajudasse. Eu pensava se esta sensação ia passar, se eu voltaria a dormir. Eu não estava conseguindo fazer mais nada direito. Eu já tinha tentado isso antes, tinha colocado fogo na casa e queria afogar a pequenina na banheira. Naquela época, foi porque ele não trabalhava. Se os vizinhos não tivessem socorrido, o botijão de gás teria explodido. Isso foi há 3 anos. Desde então me trato. Naquela época, eu escutava vozes, parece que a TV estava ligada na minha cabeça".

Ao exame do estado mental, na época do delito, apresentava alucinações auditivas. A memória não apresentava alterações. A consciência encontrava-se lúcida. O pensamento era predominantemente mágico, com ideação delirante celotípica, de suicídio e de cunho místico. Na linguagem, havia taquilalia alternando-se com mutismo. A inteligência, não testada, à avaliação clínica, é mediana. No afeto, havia o ciúme e a desconfiança, com períodos de humor depressivo, em alternância com períodos de irritabilidade. Na conduta, despontavam os delitos de homicídio, tendo por vítimas suas filhas. Houve referência de períodos anteriores de insônia, inapetência, isolacionismo, hipoatividade, tentativas de suicídio, agressividade e períodos de retraimento. Houve conduta incendiária e tentativa pretérita de filicídio.

Os dados levantados indicaram que a pericianda apresentava um transtorno afetivo bipolar, em que tipicamente períodos de mania - irritabilidade, taquilalia, agressividade, interesses místicos - alternamse com episódios depressivos (retraimento, 
hipoatividade, mutismo, descuido com os interesses usuais). O transtorno apresentava-se com sintomas maníacos e psicóticos graves.

Nos comentários médico legais, ressalta-se que o diagnóstico de transtorno afetivo bipolar corresponde ao que a lei postula como doença mental, em que há ruptura do contato com a realidade, incluindo seus aspectos éticos e normativos. Tanto seu entendimento estava comprometido como a capacidade de autodeterminação, estando sua conduta delituosa determinada por estímulos delirantes em detrimento da consideração pela realidade objetiva. Estabelecido o nexo causal entre a doença mental e o delito, caracteriza-se a inimputabilidade da pericianda, encontrando-se ela ao abrigo do artigo 26 do Código Penal, em seu caput.

Esse parecer foi acolhido pela justiça, sendo M. absolvida do crime. A pericianda recebeu uma medida de segurança de internação com prazo de 3 anos.

\section{Considerações finais}

Com a apresentação desta breve revisão bibliográfica, ilustrada com o relato de uma avaliação pericial realizada no IPF, os autores procuraram chamar a atenção para dois aspectos: a periculosidade do paciente portador de doença mental grave não-tratada e o delito de filicídio, compreendido aqui como a expressão extremada de um amplo espectro de manifestações de violência contra a criança, em especial no âmbito familiar.

Sem perder de vista a dimensão multifatorial da violência familiar tendo por vítima a criança, onde se destaca, no Brasil e em outros países emergentes, a questão social, a doença mental grave tem grande importância como fator desencadeador de certos casos de conduta filicida. Assim, o diagnóstico precoce e a implementação de medidas terapêuticas adequadas são relevantes, em se tratando de minimizar a ocorrência da violência, tanto doméstica como no âmbito da saúde mental, em suas variadas manifestações. No presente caso, por exemplo, a história revela tentativa filicida no passado.

Nestes tempos em que tanto se destaca a importância da manutenção do doente mental junto à família, é relevante salientar a importância da avaliação de risco de conduta violenta nos pacientes doentes mentais graves, com história de comorbidade, de frágil adesão às medidas terapêuticas pretéritas e sem suporte familiar adequado. Nesses casos, pode haver necessidade de medidas terapêuticas, inclusive em nível hospitalar, como recurso oportuno para a prevenção de delitos graves.

\section{Referências}

1. Silva HO, Silva JS. Análise da violência contra a criança e o adolescente segundo o ciclo de vida no Brasil. São Paulo: Global; 2005 .

2. Telles LEB. Perícias de responsabilidade penal realizadas no Instituto Psiquiátrico Forense. Multijuris: Primeiro Grau em Ação. 2007;2(3):44-9.

3. Pires JMA. Violência doméstica, violência contra crianças e adolescentes na Grande Porto Alegre. São Leopoldo: Amencar; 1998.

4. Zavaschi MLS. Abuso e maus tratos na infância e adolescência: a negação como fator conspirador ao diagnóstico. R Psiquiatr RS. 2002;24(2):209-12.

5. Rascovsky A. El filicidio. Buenos Aires: Círculo del Buen LectorBeas; 1992.

6. Kempe C, Silverman FN, Steele BF, Droegemueller W, Silver HK The battered child syndrome. JAMA. 1962;181:17-24.

7. Mendlowicz MV, Jean-Louis G, Gekker M, Rapaport MH. Neonaticide in the city of Rio de Janeiro: forensic and psycholegal perspectives. J Forensic Sci. 1999;44(4):741-5.

8. Lambie I. Mothers who kill. The crime of infanticide. Int J Law Psychiatry. 2001;24(1):71-80.

9. Pitt SE, Bale EM. Neonaticide, infanticide, and filicide: a review of the literature. Bull Am Acad Psychiatry Law. 1995;23(3):375-86.

10. Day VP, Telles LEB, Zoratto PH, Azambuja MRF, Machado DA, Silveira $M B$, et al. Violência doméstica e suas diferentes manifestações. R Psiquiatr RS. 2003;25(Supl 1):9-21.

11. Mendlowicz MV, Coscarelli PG. Infanticídio na cidade do Rio de Janeiro: perspectivas forenses e médico-legais. In: Moraes TM, organizador. Ética e psiquiatria forense. Rio de Janeiro: IPUB/ CUCA; 2001. p. 185-201.

12. Stanton J, Simpson A. Filicide: a review. Int J Law Psychiatry. 2002;25:1-14.

13. Resnick PJ. Child murder by parents: a psychiatric review of filicide. Am J Psychiatry. 1969;126(3):325-34.

14. Resnick PJ. Murder of the newborn: a psychiatric review of neonaticide. Am J Psychiatry. 1970;126(10):1414-20.

19. Castaño-Henao BL. Trastorno mental y filicidio. Rev Colomb Psiquiatria. 2005;34(1):82-9.

15. Bourget D, Gagné P. Paternal filicide in Québec. J Am Acad Psychiatry Law. 2005;33(3):354-60.

16. Menezes R. Esquizofrenia e liberdade. Reforma psiquiátrica, manicômio judicial e a era da saúde mental. Porto Alegre: Armazém Digital; 2005.

17. Nogueira JA. Atuação homicida contra os filhos: estudo clínicodinâmico de 14 casos [trabalho de conclusão de curso de especialização em psiquiatria]. Porto Alegre: UFRGS; 1976.

18. Costa ALP. Filicídio: características de uma população. R Psiquiatr RS. 1982;4(1):52-8.

20. Brasil, Ministério da Justiça. Decreto-lei no 2.484/40 (Código Penal). Brasília: Diário Oficial da União; 31/dez/1940.

21. Telles LEB, Day VP, Ávila B, Sousa FMC, Fetter HHP, Lemos NL, et al. Doença mental e outros modificadores da imputabilidade penal. R Psiquiatr RS. 2002;24(1):45-52.

22. Brasil, Ministério da Justiça. Decreto-lei no 3.689/41 (Código de Processo Penal). Brasília: Diário Oficial da União; 24/out/1941. 